\title{
Dissolution of Scrap in Hot Metal under Linz-Donawitz (LD) Steelmaking Conditions
}

\author{
Florian Markus Penz ${ }^{1, *} \mathbb{C}$, Johannes Schenk ${ }^{1,2}$, Rainer Ammer ${ }^{3}$, Gerald Klösch ${ }^{4}$ and \\ Krzysztof Pastucha ${ }^{5}$ \\ 1 K1-MET GmbH, Stahlstraße 14, A-4020 Linz, Austria; Johannes.Schenk@unileoben.ac.at \\ Chair of Ferrous Metallurgy, Montanuniversität Leoben, Franz Josef Straße 18, A-8700 Leoben, Austria \\ voestalpine Stahl GmbH, voestalpine Straße 3, A-4020 Linz, Austria; Rainer.Ammer@voestalpine.com \\ 4 voestalpine Stahl Donawitz GmbH, Kerpelystraße 199, A-8700 Leoben, Austria; \\ Gerald.Kloesch@voestalpine.com \\ 5 Primetals Technologies Austria GmbH, Turmstraße 44, A-4020 Linz, Austria; \\ Krzysztof.Pastucha@primetals.com \\ * Correspondence: Florian-Markus.Penz@K1-MET.com; Tel.: +43-3842-402-2244
}

Received: 27 November 2018; Accepted: 17 December 2018; Published: 19 December 2018

\begin{abstract}
One of the main charging materials of the Linz-Donawitz oxygen steelmaking process (LD) is scrap. Scrap acts as a coolant for the exothermic reactions inside the LD vessel and as an iron source in addition to hot metal. The optimization of the LD process is focused, amongst other factors, on thermodynamic and kinetic modelling. The results of simulations have to be validated in close to reality laboratory-scale experiments. A study was made on the dissolution behavior of common steel scrap in carbon-saturated hot metal which is charged into LD converters. In order to examine the effect of several parameters on diffusive scrap melting, the difference between stagnant and dynamic dissolution as well as the influence of the hot metal temperature were investigated. Using a literature-based equation the mass transfer coefficient of carbon between the solid scrap and the liquid hot metal was evaluated. The ranges of values of the ablation rate and the mass transfer coefficient for the appropriate systems are pointed out, resulting in a significant dependence of the investigated parameters.
\end{abstract}

Keywords: basic oxygen furnace steelmaking; mass transfer coefficient; scrap dissolution; thermodynamics; process modelling

\section{Introduction}

Since the early 1950s, oxygen steelmaking in a Linz-Donawitz oxygen steelmaking process (LD) converter has been the dominant method of crude steel production. Since the beginning, scrap has been charged as a cooling agent and an additional iron source besides hot metal. Cooling is necessary due to heat generation through the oxidation reactions of carbon, silicon, manganese, and phosphorus. The whole process cycle is influenced by the dissolution and melting behavior of scrap in hot metal. Since the early 1970s, the investigation of the melting and dissolution behavior of scrap in iron melts with different carbon contents has been investigated, whereby only a few authors have taken into account the fluid flow of the liquid phase together with the initial process composition of hot metal [1-12].

To examine the effects of several parameters on diffusive scrap melting, an experimental investigation of the melting behavior of a common steel scrap in carbon saturated hot metal was executed. This work specifically points out the differences in the melting and dissolution rate of scrap in hot metal between stagnant and turbulent fluid motion of the liquid melt. 


\section{Background of Diffusive Scrap Melting}

According to the literature, two processes control scrap melting and they change when the temperature exceeds the melting point of the scrap, which is defined by the liquidus temperature in the phase diagram for the given chemical composition of the scrap. Below the scrap melting point, the diffusion process of carbon controls the scrap dissolution and so-called diffusive melting occurs. Above the scrap melting point, forced or convective scrap melting starts. In this case, the mass transfer can be neglected since the heat transfer becomes dominant for the dissolution process $[5,6,13]$. Forced scrap melting is not relevant for this research work, since the melting point of the used steel scrap was above the hot metal temperature.

The main influence on diffusive scrap melting is the diffusive mass transport of carbon between the liquid metal and the charged scrap. Equation (1) is a mathematical model, proposed by L. Zhang and F. Oeters in ref. [6], where the mass transfer coefficient $\mathrm{k}_{\mathrm{met}}$ in $\left[\mathrm{m} \cdot \mathrm{s}^{-1}\right]$ is a second decisive factor to define the ablation rate of a scrap particle.

$$
-\frac{\mathrm{d} r}{\mathrm{~d} t}=\mathrm{k}_{\mathrm{met}} * \ln \left(\frac{\% \mathrm{C}_{\mathrm{Scrap}}-\% \mathrm{C}_{\mathrm{HM}}}{\% \mathrm{C}_{\mathrm{Scrap}}-\% \mathrm{C}_{\mathrm{liq}}}\right)
$$

In equation (1) the radius of the particle is $r$ in unit [m]. $C_{\text {liq }}$ describes the carbon concentration of the scrap on the liquidus line at a given temperature. The carbon concentrations in the scrap and hot metal are $\mathrm{C}_{\mathrm{HM}}$ and $\mathrm{C}_{\mathrm{scrap}}$ in [wt\%] [6]. In this work, the liquidus line was determined for the actual silicon and manganese content of the scrap using the $\mathrm{Fe} \mathrm{Fe}_{3} \mathrm{C}$ phase diagram generated by the FactSage ${ }^{\mathrm{TM}}$ FSstel database (licensed to Montanuniversität Leoben, Department Metallurgie; Version 7.1, @Thermfact and GTT-Technologies, Montreal, QC, Canada and Herzogenrath, Germany) [14-16].

\section{Description of the Experiment}

The steel scrap investigated in this study was an S235JR construction steel, submerged in carbon saturated hot metal. The hot metal (330 g) was charged into an alumina crucible and positioned in a high temperature vertical tube furnace. To reach the starting temperatures, the heating rate was specified at $300 \mathrm{~K} / \mathrm{min}$. Before the first and between each further dissolution experiment, a holding time of $30 \mathrm{~min}$ was set. The vertical tube furnace was flushed with nitrogen during the heating and melting process to prevent oxidation of the hot metal. The scrap geometry was cylindrical. The diameter of the cylinder was $12 \mathrm{~mm}$ and the length $30 \mathrm{~mm}$. The submerging depth into the hot metal was $25 \mathrm{~mm}$. The axial heat flow to the specimen holding was diminished through a notch. The starting temperature of the specimen was $25^{\circ} \mathrm{C}$. The axial movement of the cylinder to the melt was carried out with a vertical pneumatic controlled cylinder. In order to realize a turbulent fluid motion in the hot metal, the sample was rotated at $100 \mathrm{rpm}$ for the dynamic investigations. The determination of the real level of turbulence during the entire blowing process will, inter alia, be possible through CFD-simulation or related methods. Measurements directly in an LD converter are difficult to realize but it may be reasonable to assume that turbulent conditions are present. According to the geometric and physical parameters of the experiments and the present case of a rotating cylinder in a cylindrical crucible the theory of Taylor-Couette flow is used to define when laminar flow becomes unstable and further turbulent. The mathematical executions are not explained in detail in this work but are well described by A. Esser and S. Grossmann in [17] or A. Racina in [18]. For the present system a rotating sample with $100 \mathrm{rpm}$ was found to be definitely in turbulent mixing regime. For static conditions, stirring by rotation of the cylinder was not performed.

To determine the effect of the initial temperature of the hot metal, three starting temperatures were defined $\left(1305^{\circ} \mathrm{C}, 1370{ }^{\circ} \mathrm{C}\right.$, and $\left.1450^{\circ} \mathrm{C}\right)$. Through pre-experiments as well as a heat and mass balance, published by the authors in ref. [19] the equilibrium temperature between the scrap center 
and the hot metal was reached after less than $10 \mathrm{~s}$. The starting and equilibrium temperatures as well as the chemical composition of the hot metal and the steel scrap are listed in Table 1.

Table 1. Specification of the hot metal and the scrap.

\begin{tabular}{ccc}
\hline Definition & Hot metal & Scrap \\
\hline Carbon content [wt $\%$ ] & 4.58 & 0.1 \\
Silicon content [wt $\%$ ] & 0.37 & 0.0733 \\
Manganese content [wt $\%]$ & 0.63 & 0.479 \\
Phosphorus content [wt $\%$ ] & 0.07 & 0.01 \\
Mass [g] & 330 & 26.3 \\
Initial temperature $\left[{ }^{\circ} \mathrm{C}\right]$ & $1305 / 1370 / 1450$ & 25 \\
Equilibrium temperature $\left[{ }^{\circ} \mathrm{C}\right]$ & $1230 / 1300 / 1385$ & $1230 / 1300 / 1385$ \\
\hline
\end{tabular}

To fulfil the variables for Equation (1), the carbon concentrations on the liquidus line of the scrap $\left(\mathrm{C}_{\text {liq }}\right)$ for the three determined equilibrium temperatures, given in Table 1 , are shown in the appropriate phase diagram of the scrap in Figure 1. In the same figure the red line defines the liquidus line of the used scrap. The carbon concentrations $\left(\mathrm{C}_{\text {liq }}\right)$ are marked with the star symbol and their values are written beside it.

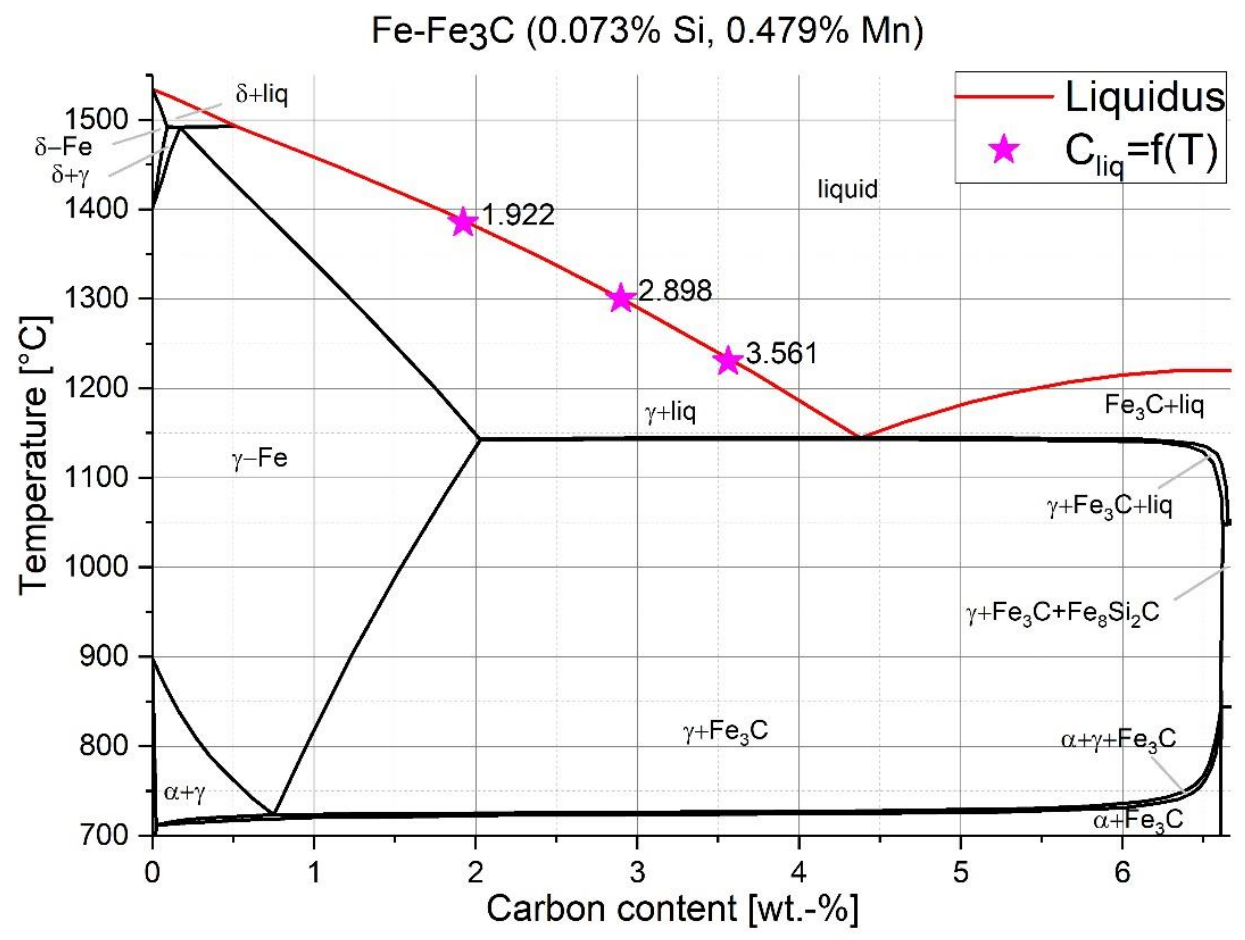

Figure 1. Carbon concentration of the scrap on the liquidus line at a given temperature.

The weight of the cylinder was measured before each experiment. After a defined dissolution time, the sample was extracted from the melt. Immediately after the extraction, the sample was quenched in water to avoid weight changes through oxidation. For the evaluation of the ablation rate $(\mathrm{dr} / \mathrm{dt})$, the radius was determined through the mass $\left(m_{\Delta t}\right)$ of the sample after the measured dissolution time. For this evaluation, the density of the cylinder, defined by Equation (2), published by Miettinen in ref. [20], was used. The density $\rho_{T=T_{e q}}$ is assumed to be equal to the density at the equilibrium temperature ( $T=T_{e q}$, austenitic) as well as the density of the hot metal. It was observed that only melting in the radial direction occurred, which can be explained through local density differences according to the temperature gradient in the boundary layer of the hot metal. Therefore, the length $l$ of the cylinder was assumed to be constant for the evaluation of the radius $r$ after a certain dissolution 
time $\Delta t$. Further hot metal droplets stuck to the ground surface of the cylinder after its removal from the melt. The adherent hemispheres were included for the determination of the radius $r_{\Delta t}$. Due to the fact that the hot metal droplet is not always a perfect hemisphere, it has to be multiplied by a geometric factor $\mathrm{g}$. The factor is 1 if the droplet is a hemisphere or 0 if there is no hot metal sticking on the ground surface. The geometric factor was determined through pictures, which were taken at eight circumferential positions. The equation for the determination of the radius after a certain time $r_{\Delta t}$ was done by goal seek application with Microsoft Excel and is shown in Equation (3), where $m_{\Delta t}$ is the mass of the cylinder after the defined submerging period.

$$
\begin{gathered}
\rho_{T=T_{e q}}=8099.79-0.506 T+(-118.26+0.00739 T) * \mathrm{C}_{\mathrm{C}, \mathrm{scr}}-68.24 * \mathrm{C}_{\mathrm{Si}, \mathrm{scr}}-6.01 * \mathrm{C}_{\mathrm{Mn}, \mathrm{scr}} \\
0=\frac{2}{3} * r_{\Delta t}^{3} * g+r_{\Delta t}^{2} * l-\frac{m_{\Delta t}}{\rho_{T=T_{e q}} * \pi}
\end{gathered}
$$

The derivates of the ablation rate $(\Delta r / \Delta t)$ were solved by a Lagrange polynomial of the second grade for uneven time steps. The basic polynomial used is shown in Equation (4) [21].

$$
\begin{aligned}
f^{\prime}(x)=f\left(x_{i-1}\right) & \frac{2 x-x_{i}-x_{i+1}}{\left(x_{i-1}-x_{i}\right) *\left(x_{i-1}-x_{i+1}\right)}+f\left(x_{i}\right) \frac{2 x-x_{i-1}-x_{i+1}}{\left(x_{i}-x_{i-1}\right) *\left(x_{i}-x_{i+1}\right)} \\
& +f\left(x_{i+1}\right) \frac{2 x-x_{i-1}-x_{i}}{\left(x_{i+1}-x_{i-1}\right) *\left(x_{i+1}-x_{i}\right)}
\end{aligned}
$$

In Equation (4), $x$ is the value where the derivative has to be estimated, which in this case is the radius $r$ as derivative from the time.

\section{Discussion of the Experimental Results}

The experimental data is based on a test series where three to six specimens were submerged for a specific time into hot metal. The submerging times were $10 \mathrm{~s}, 20 \mathrm{~s}, 30 \mathrm{~s}, 60 \mathrm{~s}, 120 \mathrm{~s}, 180 \mathrm{~s}$, and $240 \mathrm{~s}$. At the highest equilibrium temperature $140 \mathrm{~s}$ was the longest submerging time. From each cylinder, photographs were made in the circumferential position for further processing. In Figure 2 the cylinders after the given submerging time are shown in comparison to the initial state of the cylinder.

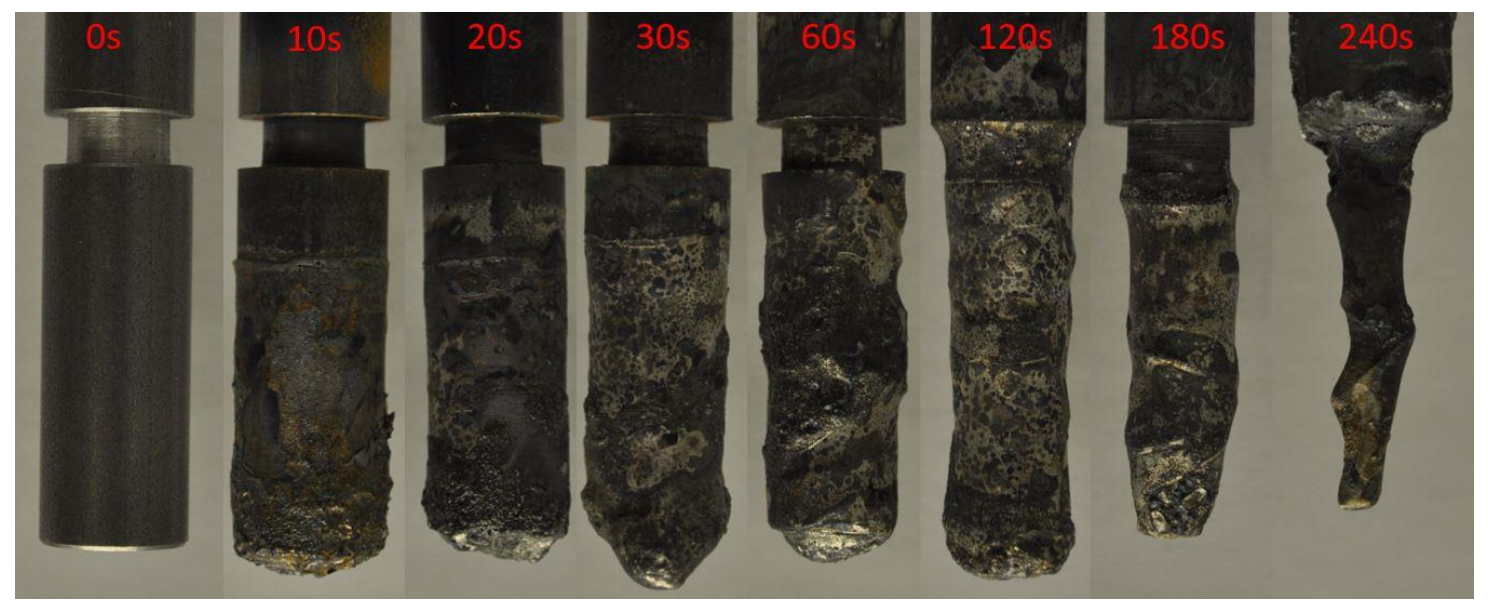

Figure 2. Recent photography's of the steel cylinders after a specific dissolution time (red marks) in comparison to the initial state $(0 \mathrm{~s})$.

In Figure 3 the calculated dimensionless average radius, using Equation (3), is shown for static approaches (no rotation of the sample). Figure 4 shows the determined values in turbulent conditions (dynamic sample, rotation velocity $100 \mathrm{rpm}$ ) inside the hot metal, which are more valuable for the conditions during the LD process, where high turbulence according to the oxygen blowing arises. The light areas in Figures 3 and 4 show the standard deviation of the measurements. Especially at the 
higher temperatures and long dissolution times, problems of oxidation through air inside the furnace lead to higher fluctuations of the final determined radius.

In the initial stage of the dissolution, a small shell formation appears that lasts longer the lower the temperature of the liquid hot metal. At an equilibrium temperature of $1385^{\circ} \mathrm{C}$ no shell formation is obvious after $10 \mathrm{~s}$. In this case, the freezing and melting of the hot metal layer are already finished after the first measurement point. Furthermore, it is clearly shown that the shell formation will be shorter during turbulent conditions. With increasing temperature, the decrease of the radius is faster. This effect appears in both settings.

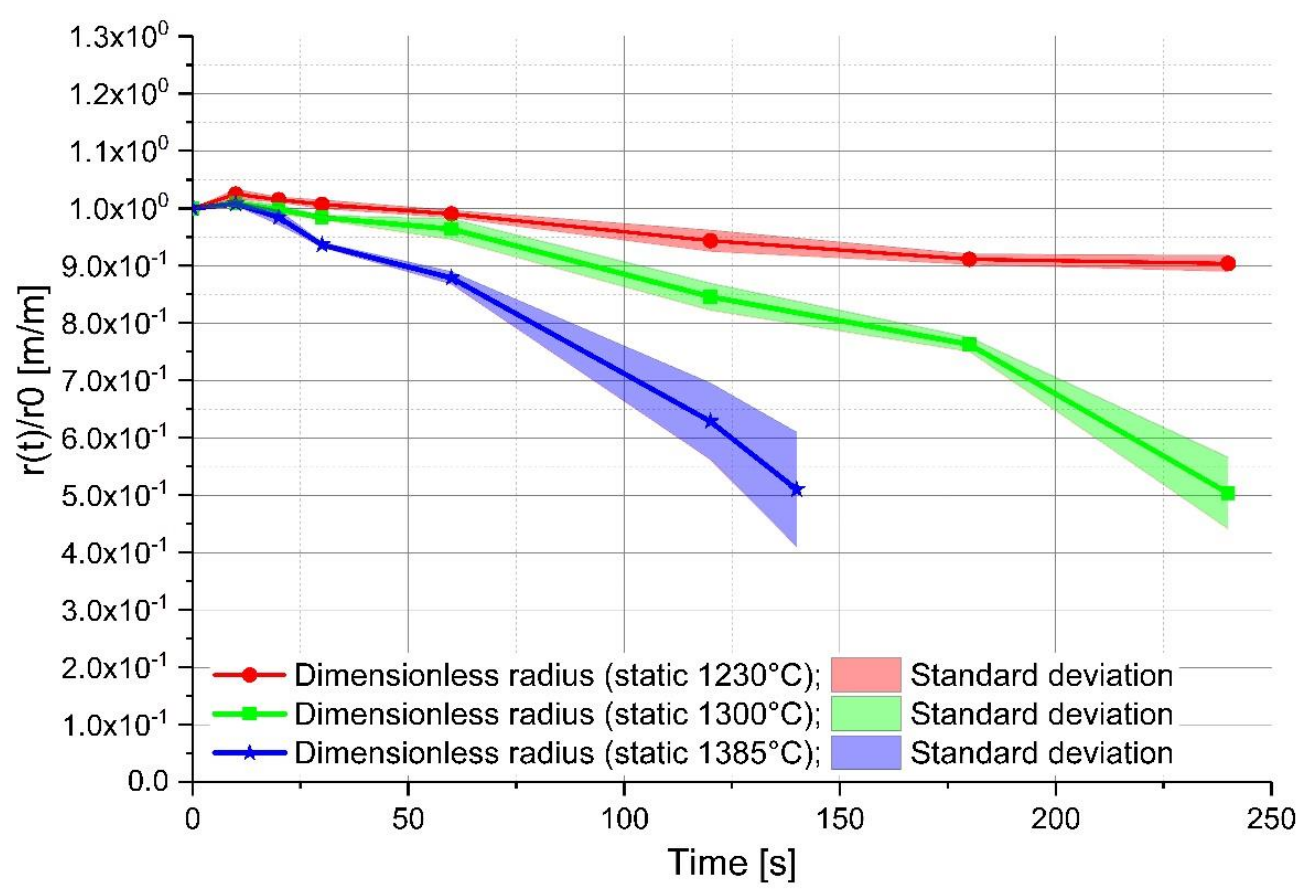

Figure 3. Dimensionless radius of the experiment with stagnant hot metal (static approach).

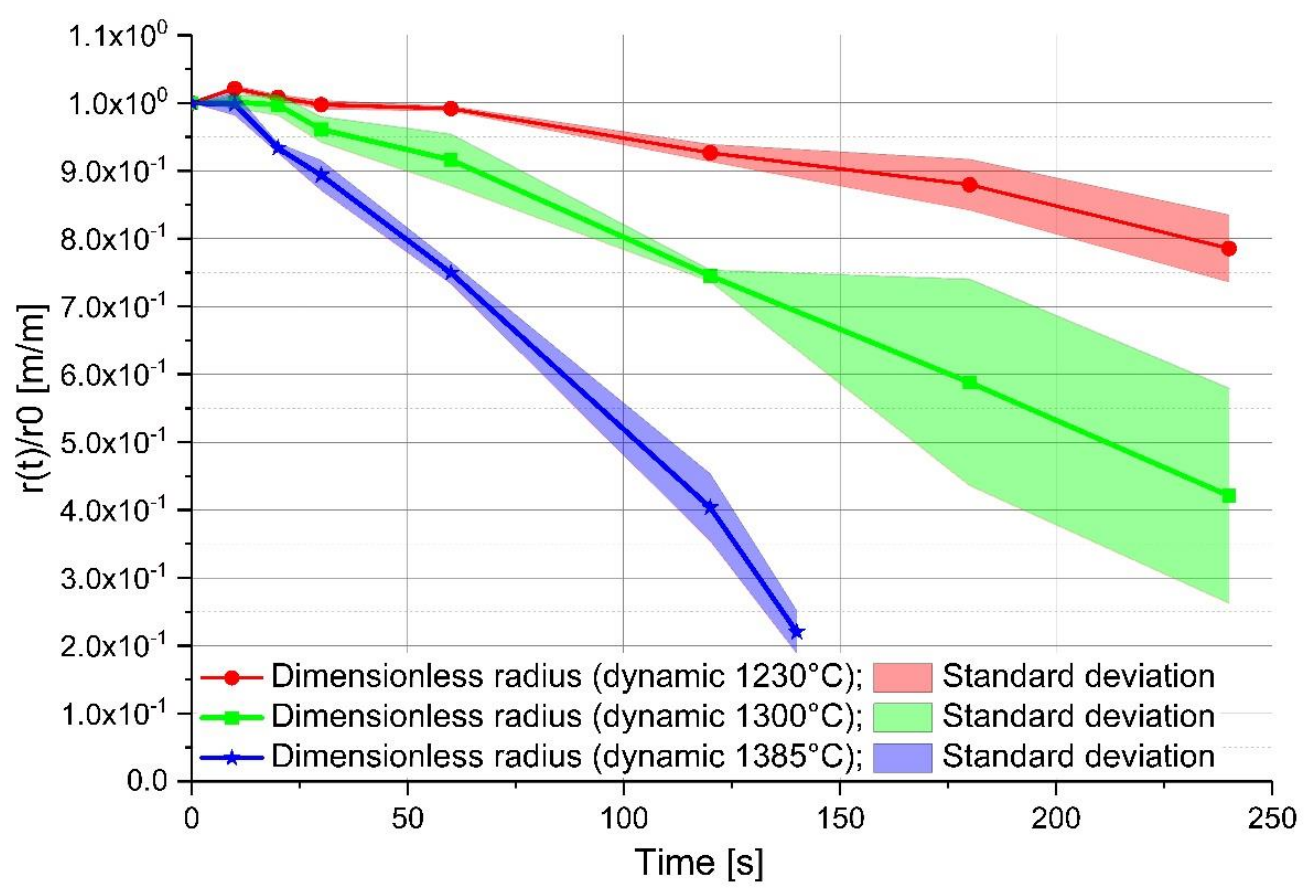

Figure 4. Dimensionless radius of the experiment with turbulent conditions in hot metal (dynamic approach). 
In Figure 4 it can be seen that diffusive melting proceeds faster in comparison to static conditions. After a process time of $150 \mathrm{~s}$ and an equilibrium temperature of $1385^{\circ} \mathrm{C}$, the cylinder dissolved completely.

Based on the determined radius, the derivates of the ablation rates were quantified based on a second grade Lagrange polynomial. The graphical results are shown in Figure 5. It is visible that the ablation rate stays close to constant after shell formation. This could be observed at the two lower equilibrium temperatures. At the equilibrium temperature of $1385^{\circ} \mathrm{C}$, a slight decrease in the ablation rate is visible. This is a result of the oxidizing atmosphere in the vertical tube furnace. The surface of the sample that is not submerged in the hot metal starts to be oxidized after long holding times and higher temperatures. At all temperatures, the absolute value $(|\Delta r / \Delta t|)$ of the ablation rate under turbulent hot metal conditions is higher than under static surroundings, which means that the scrap melts faster under turbulent conditions. This is explainable due to the higher mass transport from the sample surface to the melt according to the turbulence. In Equation (1) there is no factor for turbulence included, so a modification has to be defined.

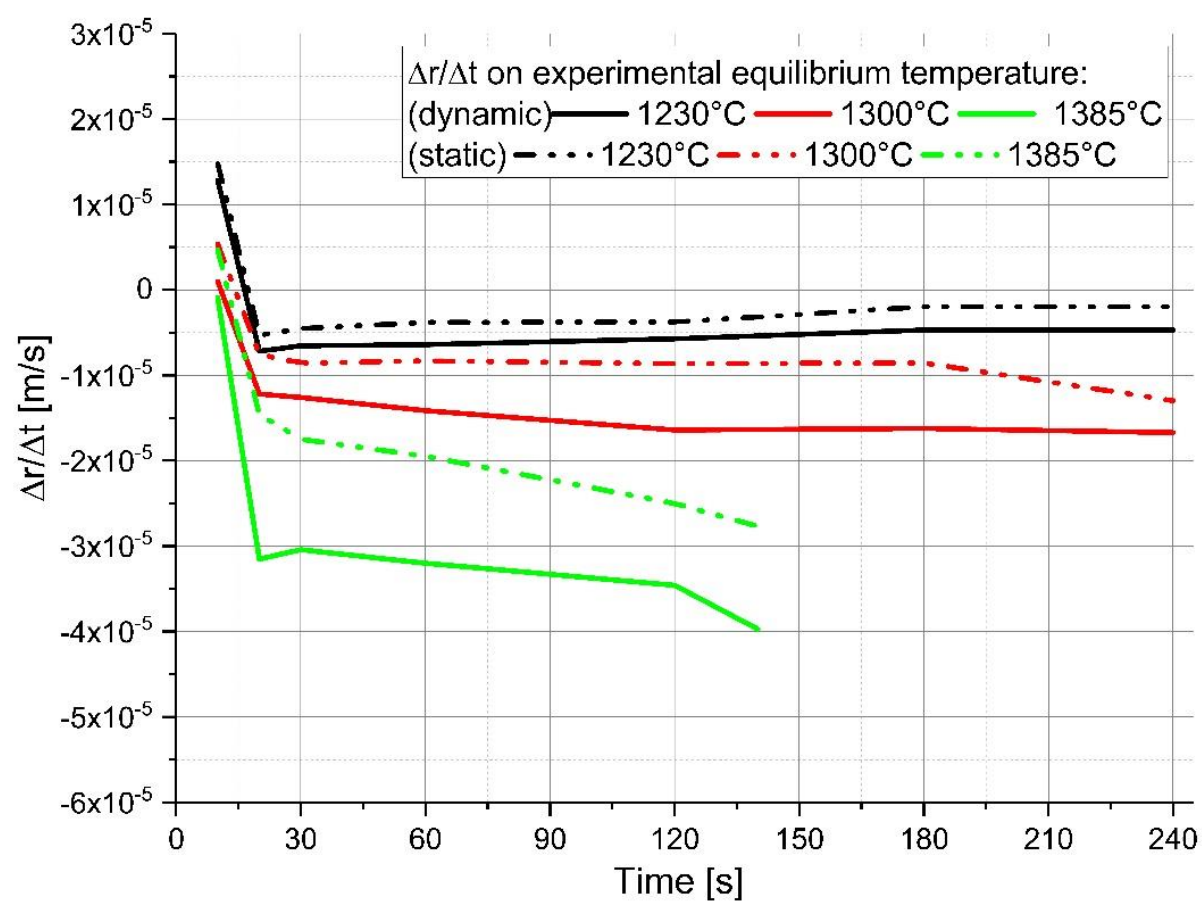

Figure 5. Comparison of the radial ablation rates in stagnant or turbulent conditions of the liquid hot metal with different equilibrium temperatures.

The mass transfer coefficients for the appropriate systems were evaluated with Equation (1) using the chemical parameters from Table 1 and Figure 1 as well as the determined derivates. The mass transfer coefficients for the stagnant and dynamic systems are presented in Figure 6 and listed in Table 2. After the shell formation ends, a quite constant mass transfer coefficient occurs at the temperatures of $1230{ }^{\circ} \mathrm{C}$ and $1300{ }^{\circ} \mathrm{C}$. In all cases, the mass transfer is higher under turbulent conditions in the hot metal. At a temperature of $1385^{\circ} \mathrm{C}$, again a slight increase in the mass transfer with increasing dissolution time is obvious according to the oxidation of the sample holding device.

Table 2 lists the range of the calculated ablation rate and the mass transfer coefficients above $20 \mathrm{~s}$ of dissolution time. In the case, presented in this work, the freezing of a hot metal layer and its melting is finished. As shown in Table 2, the ablation rate is always negative after $20 \mathrm{~s}$ which means the scrap melts according to the diffusive melting theory. Thereby, it is clearly shown that the mass transfer is influenced strongly by the temperature and the experimental condition. Higher temperatures and a turbulent surrounding increase the mass transfer. 


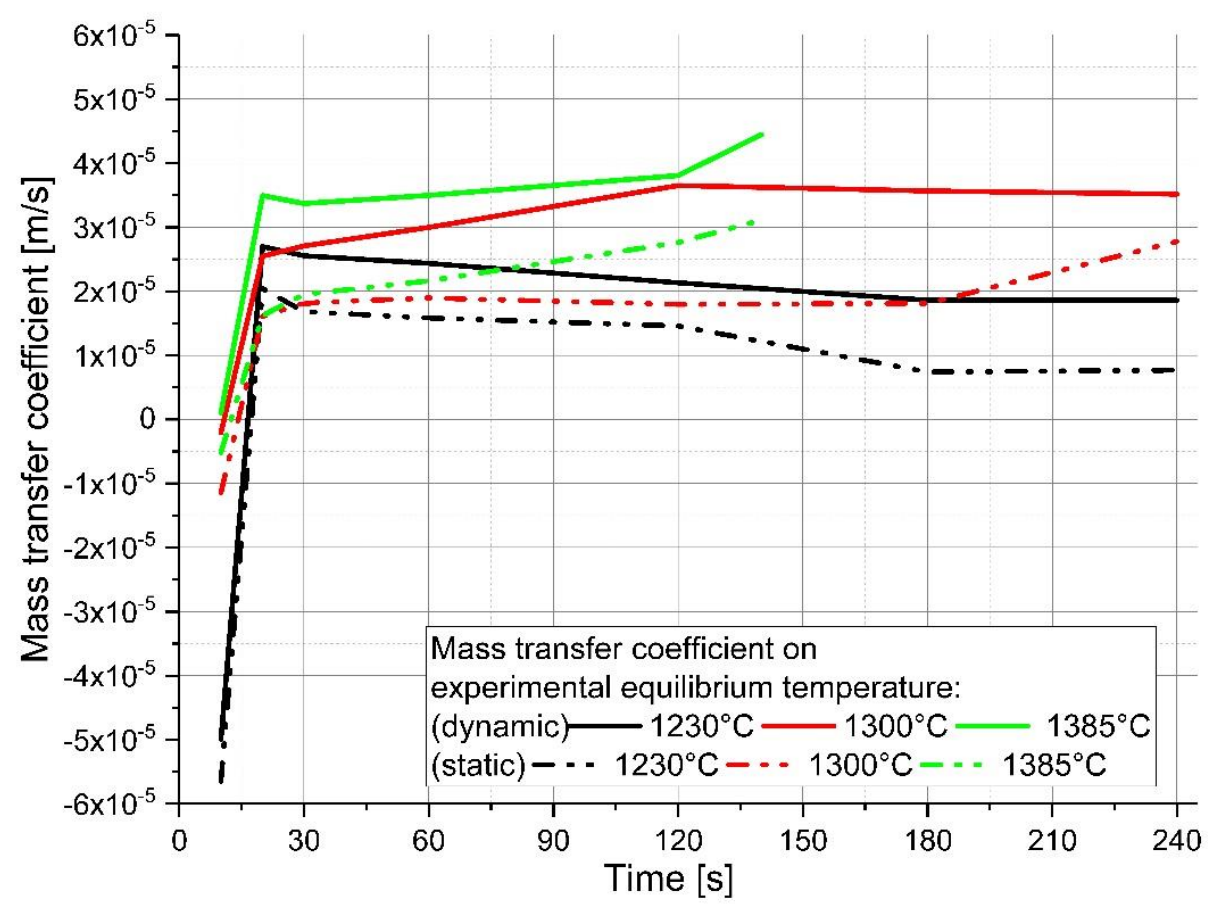

Figure 6. Comparison of the determined mass transfer coefficients under stagnant or turbulent conditions of the liquid hot metal with different equilibrium temperatures.

Table 2. Range of the calculated ablation rate and mass transfer coefficient above $20 \mathrm{~s}$ dissolution time.

\begin{tabular}{ccccccc}
\hline $\begin{array}{c}\text { Equilibrium } \\
\text { temperature }\left[{ }^{\circ} \mathrm{C}\right]\end{array}$ & 1230 & 1230 & 1300 & 1300 & 1385 & 1385 \\
Experimental condition & static & dynamic & static & dynamic & static & dynamic \\
Ablation rate & -1.98 to & -4.68 to & -7.5 to & -12.1 to & -14.6 to & -30.4 to \\
{$\left[(\mathbf{m} / \mathbf{s}) \times \mathbf{1 0}^{-6}\right]$} & -5.30 & -7.19 & -12.9 & -16.7 & -27.7 & -39.7 \\
Mass transfer coefficient & $7.39-20.4$ & $18.5-27.0$ & $16.1-26.8$ & $25.5-36.5$ & $18.2-31.1$ & $33.7-44.4$ \\
{$\left[(\mathbf{m} / \mathbf{s}) \times \mathbf{1 0}^{-6}\right]$} & & & & & & \\
\hline
\end{tabular}

\section{Discussion}

The intention of this work was to present the results of laboratory-scale experiments on the dissolution and melting behavior of common construction steel scrap in hot metal under stagnant or turbulent conditions of the melt and with a variation in temperature. The conditions were used because they are similar to the initial stages of the LD steelmaking process.

For the investigation of the differences between the two assumed conditions, the ablation rate of the radius of the dissolved scrap cylinder was determined. A shell formation of the hot metal on the scrap surface occurred in the initial stages at the experiment equilibrium temperatures of $1230{ }^{\circ} \mathrm{C}$ and $1300{ }^{\circ} \mathrm{C}$. It was clearly pointed out that the shell formation lasts longer the lower the equilibrium temperature. At the highest temperature, the shell formation and its melting is finished after the first measurement point of a submerging time of $10 \mathrm{~s}$. Turbulent conditions decrease the time of shell formation significantly. Based on the measured and calculated radius, the derivates for the ablation rate of the radius were determined using a second grade Lagrange polynomial. The ablation rate observed was shown to be constant after the turning point of the shell formation at temperatures of $1230{ }^{\circ} \mathrm{C}$ and $1300^{\circ} \mathrm{C}$. At $1385^{\circ} \mathrm{C}$, a decrease in the ablation rate was visible. Finally, it was observed that turbulent bath conditions have a higher absolute value of the ablation rate than in a stagnant melt.

In summary, the results of the work clearly indicate that the actual temperature and the motion of the melt have a strong impact on the melting and dissolution behavior of scrap. More research has to be done to develop a close to reality equation for the melting and dissolution behavior under the LD steelmaking process conditions. The conclusions should be used in further works to improve the 
theoretical and practical description of the scrap melting for online and offline dynamic LD converter models, used in the industry. Better predictions of scrap melting may result in a decrease in lance damages due to breakage induced by non-molten big scrap pieces. Furthermore, a more precise description of the scrap melting and dissolution may decrease tap-to-tap times.

Author Contributions: Conceptualization, F.M.P.; Data curation, F.M.P.; Investigation, F.M.P.; Methodology, F.M.P.; Project administration, F.M.P., J.S. and K.P.; Resources, F.M.P.; Software, F.M.P. and J.S.; Supervision, F.M.P. and J.S.; Validation, J.S., R.A., G.K., and K.P.; Visualization, F.M.P.; Writing—original draft, F.M.P.; Writing一review and editing, F.M.P., J.S., R.A., G.K., and K.P.

Funding: This research project is co-funded by public financial resources from the Austrian Competence Center Programme COMET and by the industrial partners voestalpine Stahl, voestalpine Stahl Donawitz, and Primetals Technologies Austria.

Acknowledgments: The authors gratefully acknowledge the funding support of K1-MET GmbH, metallurgical competence centre. The research programme of the K1-MET competence centre is supported by COMET (Competence Centre for Excellent Technologies), the Austrian programme for competence centres. COMET is funded by the Federal Ministry for Transport, Innovation and Technology, the Federal Ministry for Science, Research and Economy, the provinces of Upper Austria, Tyrol, and Styria as well as the Styrian Business Promotion Agency (SFG).

Conflicts of Interest: The authors declare no conflict of interest.

\section{References}

1. Turkdogan, E.T. Fundamentals of Steelmaking; The Institute of Materials: London, UK, 1996; pp. 209-244.

2. Ghosh, A.; Chatterjee, A. Ironmaking and Steelmaking Theory and Practice; PHI Learning Private Limited: Delhi, India, 2015; pp. 285-292.

3. Asai, S.; Muchi, I. Effect of scrap melting on the process variables in LD converter caused by the change of operating conditions. Trans. ISIJ 1971, 11, 107-115.

4. Gaye, H.; Wanin, M.; Gugliermina, P.; Schittly, P. Kinetics of scrap dissolution in the converter. Theoretical model and plant experimentation. In Proceedings of the 68th Steelmaking Conference, AIME, Detroit, MI, USA, 14-17 April 1985; pp. 91-103.

5. Isobe, K.; Maede, H.; Ozawa, K.; Umezawa, K.; Saito, C. Analysis of the scrap melting rate in high carbon molten iron. ISIJ 1990, 76, 2033-2040.

6. Zhang, L.; Oeters, F. Schmelzen und Mischen von Legierungsstoffen in Stahlschmelzen; Verlag Stahleisen GmbH: Düsseldorf, Germany, 2012; pp. 38-40.

7. Szekely, J.; Chuang, Y.K.; Hlinka, J.W. The melting and dissolution of low-carbon steels in iron-carbon melts. Metall. Trans. 1972, 3, 2825-2833. [CrossRef]

8. Shukla, A.K.; Deo, B.; Robertson, D.G.C. Scrap Dissolution in Molten Iron Containing Carbon for the Case of Coupled Heat and Mass Transfer Control. Metall. Mater. Trans. B 2013, 44, 1407-1427. [CrossRef]

9. Den Hartog, H.W.; Kreyger, P.J.; Snoeijer, A.B. Dynamic model of the dissolution of scrap in BOF process. CRM Rep. 1973, 37, 13-22.

10. Kawakami, M.; Takatani, K.; Brabie, L.C. Heat and Mass Transfer Analysis of Scrap Melting in Steel Bath. Tetsu-to-Hagané 1999, 85, 658-665. [CrossRef]

11. Kruskopf, A.; Holappa, L. Scrap melting model for steel converter founded on interfacial solid/liquid phenomena. Metall. Res. Technol. 2018, 115, 201-208. [CrossRef]

12. Sethi, G.; Shukla, A.K.; Das, P.C.; Chandra, P.; Deo, B. Theoretical Aspects of Scrap Dissolution in Oxygen Steelmaking Converters. In Proceedings of the AISTech 2004 Proceedings Volume II, Nashville, TN, USA, 15-17 September 2014; pp. 915-926.

13. Medzhibozhskiy, M.Y. Basis of Thermodynamic and Kinetic of Steelmaking; Vischa shkola: Kyiv, Ukraine, 1979; p. 229.

14. Lytvynyuk, Y.; Schenk, J.; Hiebler, M.; Sormann, A. Thermodynamic and Kinetic Model of the Converter Steelmaking Process. Part 1: The Description of the BOF Model. Steel Res. Int. 2014, 85, 537-543. [CrossRef]

15. Penz, F.M.; Bundschuh, P.; Schenk, J.; Panhofer, H.; Pastucha, K.; Paul, A. Effect of Scrap Composition on the Thermodynamics of Kinetic Modelling of BOF Converter. In Proceedings of the 2nd VDEh-ISIJ-JK Symposium, Stockholm, Sweden, 12-13 June 2017; pp. 124-135. 
16. Zarl, M. Development and Evaluation of a BOF Pre-Processor Model. Master's Thesis, Montanuniversität Leoben, Leoben, Austria, 2017.

17. Esser, A.; Grossmann, S. Analytic expression for Taylor-Couette stability boundary. Phys. Fluids 1996, 8, 1814-1819. [CrossRef]

18. Racina, A. Vermischung in Taylor-Couette Strömung; Universitätsverlag: Karlsruhe, Germany, 2009; pp. $29-40$.

19. Penz, F.M.; Schenk, J.; Ammer, R.; Maunz, B.; Pastucha, K. Dissolution behavior of ULC steel in carbon saturated hot metal. In Proceedings of the 2nd International Congress on Science and Technology of Steelmaking, Venice/Mestre, Italy, 12-13 June 2018. CD-ROM.

20. Miettinen, J. Calculation of solidification-related thermophysical properties for steels. Metall. Mater. Trans. $B$ 2018, 28 B, 281-297. [CrossRef]

21. Chapra, S.C.; Canale, R.P. Métodos Numéricos para Engenharia, 4th ed.; McGraw-Hill International do Brasil Ltda: São Paulo, Brazil, 2008; p. 549.

(C) 2018 by the authors. Licensee MDPI, Basel, Switzerland. This article is an open access article distributed under the terms and conditions of the Creative Commons Attribution (CC BY) license (http:/ / creativecommons.org/licenses/by/4.0/). 